\title{
Short term effects of maternal obesity on mother and fetus: a prospective study
}

\author{
Amrutha R. Thota ${ }^{1 *}$, Ambarisha Bhandiwad ${ }^{1}$, Vineet Sakhireddy ${ }^{2}$
}

\begin{abstract}
${ }^{1}$ Department of Obstetrics and Gynecology, JSS University, Mysore, Karnataka, India
${ }^{2}$ Department of Urology, Amrita Institute of Medical Sciences, Kochi, Kerala, India
\end{abstract}

Received: 20 July 2018

Accepted: 23 June 2018

\section{*Correspondence:}

Dr. Amrutha R. Thota,

E-mail: thota.amrutha@gmail.com

Copyright: (c) the author(s), publisher and licensee Medip Academy. This is an open-access article distributed under the terms of the Creative Commons Attribution Non-Commercial License, which permits unrestricted non-commercial use, distribution, and reproduction in any medium, provided the original work is properly cited.

\begin{abstract}
Background: Obesity is such a common health care problem of female population that have major impact on pregnancy. The worldwide prevalence of obesity is more than doubled in between 1980 and 2015. The objectives of present study are to observe whether obese women have an increased risk of pregnancy related complications and adverse fetal outcome and also to compare pregnancy outcomes in different classes of BMI in obese group.

Methods: A prospective observational study conducted in OBG department JSS Hospital, Mysore from November 2014 to July 2016. All pregnant women attending OPD and inpatients of antenatal wards were screened for prepregnancy BMI. Total number of singleton births were 5727 in our institution. Out of which 314 obese pregnant women were included in the study group, remaining 5413 non-obese pregnant mothers were taken as control group respectively. They are closely monitored in every antenatal visit for development of complications such as preeclampsia, gestational diabetes mellitus, increased rate of caesarean section and presence of macrosomia (B.wt $>3.5 \mathrm{~kg}$ ).

Results: In comparison to normal BMI pregnant women, obese mothers had an increased risk of gestational hypertension (16.9\% versus $2.0 \%$, OR-2.3) gestational diabetes mellitus (35.7\% versus 3.1\%, OR-2.84), preeclampsia (23.9\% versus $5 \%, 0 \mathrm{R}-1.64)$ cesarean sections (75.2\% versus $65.4 \%)$, macrosomia $(45.9 \%$ versus $22 \%$, OR-1.64), it was also found that as BMI increases the incidence of these complications increase as seen in different classes of obese population.

Conclusions: Pregnancy associated with obesity is considered as a high-risk pregnancy and obesity being a modifiable risk factor, educating women in early pregnancy and preconceptional counseling regarding harmful effects of obesity and information regarding appropriate gestational weight gain is essential.
\end{abstract}

Keywords: Cesarean section, Gestational diabetes mellitus, Macrosomia, Pre-eclampsia

\section{INTRODUCTION}

Obesity is a considered as a pandemic in the $21^{\text {st }}$ century. The prevalence rates of obesity in the general population have increased substantially in the past 20 years.

The latest projections from WHO show 2.3 billion were overweight and 700 million were obese in $2015 .^{1}$ While the rising figures include the population as a whole and are of great concern, what is even more alarming is the number of women of childbearing age who are overweight or obese.

Prevalence of obesity is doubled among women from $16.5 \%$ to $33.2 \%$ in the last few years. The national health and nutritional examination survey indicated that more than one third of reproductive age is overweight and $8 \%$ are extremely obese. ${ }^{2}$ 
According to National Family Health Survey (NHFS-3) 2005-06 of India. The prevalence of obesity among Indian women between 15-49 yrs shown an increase by 24.52 per cent in a 7 -year period. ${ }^{3}$

ICMR-INDIAB phase1 further stated that an increase of 24.1 per cent expecting a further increase by 91.3 per cent in a 5-year period and, on the whole, an increase by 127.4 per cent over a 12 years period. ${ }^{3}$ The obstetrical population has not been immune to this pandemic. According to Maternity Experiences Survey (MES) carried in 2006-2007, approximately one-third of women aged 15 and older began their pregnancy were either overweight or obese. ${ }^{4}$

This increase in the prevalence of maternal obesity is of great concern as it has been found to be associated with adverse health outcomes affecting the mother and her fetus, neonate and child such as hypertensive disorders of pregnancy, gestational diabetes mellitus, thromboembolic complications, excessive gestational weight gain and retainment after delivery, miscarriage (Yogev and Catalano, 2009), increased risk for a caesarean section, labour induction, prolonged delivery, shoulder dystocia, excessive blood loss, macrosomia/LGA, early neonatal deaths. ${ }^{5}$

Unfortunately, the association between obesity and adverse pregnancy outcomes is not universally acknowledged, which only serves to perpetuate the problem hence this study aimed to test the hypothesis that obesity, as determined by maternal body mass index (BMI), is associated with adverse outcomes for mother and baby, and to quantify this risk.

The objective of the study was to analyse whether obese pregnant women have an increased risk of complications compared to women with normal BMI such as complications in mother (Pre-eclampsia and gestational hypertension, gestational diabetes mellitus, caesarean delivery), Complications in fetus (macrosomia) and to compare pregnancy outcomes in different classes of BMI among obese women.

\section{METHODS}

It is a prospective observational study conducted in OBG Department, JSS Medical college and Hospital, Mysore from November 2014 to July 2016. All obese pregnant women (i.e pre-pregnancy BMI/BMI at the first antenatal visit $>30 \mathrm{~kg} / \mathrm{m}^{2}$ ) attending OPD and those admitted in wards were taken as subjects.

\section{Inclusion criteria}

- All pregnant women with singleton pregnancies, booked with the hospital

- Regular with follow up till delivery.

\section{Exclusion criteria}

- Unbooked cases with no data on pregnancy, delivery or birth outcome

- Twin pregnancies, abortions, fetal deaths

- Lost to follow up

- Known case of hypertensives, diabetes mellitus and thrombophilias.

All mothers were followed up with regular antenatal check-ups with measurement of blood pressure and investigations such as urine protein, OGCT with $75 \mathrm{gm}$ glucose were done. They are closely monitored in every antenatal visit for any development of pre-eclampsia, gestational diabetes mellitus. They were admitted in due time in our antenatal ward for timely management and intervention.

Relevant complications if any, were treated as per protocol. Mode of delivery was decided according to obstetric indication. They are monitored in their hospital stay and till the end of delivery to know the rate caesarean sections and prevalence of macrosomic babies.

\section{Statistical analysis}

Statistics used were descriptives, cross tabs, odd's ratio, All the statistical calculations were done through SPSS for windows ( $\mathrm{v}$ 16.0).

\section{RESULTS}

For the given time period, a total of 5727 singleton pregnant women were followed up to delivery. Out of which 314 obese pregnant women were taken as a study group for the present study.

The remaining sample was considered as control group consists of 5413 non-obese women. The incidence accounts to $5.48 \%$ of the total sample of singleton deliveries.

Table 1: Age and parity analysis.

\begin{tabular}{|llllll|}
\hline Age & Obese $(n=314)$ & Non-obese $(n=5413)$ & parity & Obese $(\mathbf{n = 3 1 4})$ & Non-0bese $(\mathrm{n}=5413)$ \\
\hline $18-24$ & $103(32.8 \%)$ & $2636(48.7 \%)$ & primigravida & $175(55.7 \%)$ & $3085(57 \%)$ \\
\hline $25-29$ & $127(40.4 \%)$ & $2165(40 \%)$ & multigravida & $139(44.3 \%)$ & $2327(43 \%)$ \\
\hline$>30$ & $84(26.8 \%)$ & $612(11.3 \%)$ & & & \\
\hline
\end{tabular}


The maximum was in the age group of 18-24 years. Parity analysis of both the groups were similar with no statistical significance.

Majority of the sample (76.10\%) of the study group come under class -1 (30-34.9) $\mathrm{kg} / \mathrm{m}^{2}$ BMI. Mean BMI for the group is $34.1 \mathrm{~kg} / \mathrm{m}^{2}$ (Table 1 ). The complications studied have significant increase in obese compared to non-obese group.

In obese group the rate of emergency LSCS is greater than that of elective LSCS (43.3\%vs30.7\%). The rate of emergency LSCS in obese group is higher than that of non-obese group $(43.3 \%$ vs $40.6 \%)$ but not found to be statistically significant (Table 2).

Table 2: Comparison of complications in obese and non-obese.

\begin{tabular}{|c|c|c|c|c|}
\hline Complications & Obese $(n=314)$ & Non-obese $(n=5413)$ & P value & Odd's ratio (95\% CI) \\
\hline Gestational hypertension & $53(16.9 \%)$ & $107(2.0 \%)$ & 0.0005 & $2.31(2.66-1.95)$ \\
\hline Pre-eclampsia & $75(23.9 \%)$ & $309(5.7 \%)$ & 0.0002 & $1.64(1.92-1.36)$ \\
\hline Mild & $52(16.6 \%)$ & $190(3.5 \%)$ & & \\
\hline Severe & $23(17 \%)$ & $119(2.1 \%)$ & & \\
\hline Gestational diabetes mellitus & $112(35.7 \%)$ & $166(3.1 \%)$ & 0.0001 & $2.86(3.14-2.20)$ \\
\hline Diet & $75(23.9 \%)$ & $107(1.97 \%)$ & & \\
\hline Insulin & $37(11.8 \%)$ & $59(1.08 \%)$ & & \\
\hline Macrosomia (>3.5 kg) & $144(45.9 \%)$ & $1203(22.2 \%)$ & 0.0002 & $1.10(0.85-1.36)$ \\
\hline \multicolumn{5}{|l|}{ Mode of delivery } \\
\hline Cesarean section & $236(75.2 \%)$ & $3540(65.4 \%)$ & 0.001 & \\
\hline Emergency LSCS & $136(43.3 \%)$ & $2200(40.6 \%)$ & & \\
\hline Elective LSCS & $97(30.7 \%)$ & $1343(24.8 \%)$ & & \\
\hline NVD & $78(24.8 \%)$ & $1873(34.6 \%)$ & & \\
\hline Complications & Obese $(n=314)$ & Non-obese $(n=5413)$ & P value & Odd's ratio $(95 \% \mathrm{CI})$ \\
\hline Gestational hypertension & $53(16.9 \%)$ & $107(2.0 \%)$ & 0.0005 & $2.31(2.66-1.95)$ \\
\hline Pre-eclampsia & $75(23.9 \%)$ & $309(5.7 \%)$ & 0.0002 & $1.64(1.92-1.36)$ \\
\hline Mild & $52(16.6 \%)$ & $190(3.5 \%)$ & & \\
\hline Severe & $23(17 \%)$ & $119(2.1 \%)$ & & \\
\hline Gestational diabetes mellitus & $112(35.7 \%)$ & $166(3.1 \%)$ & 0.0001 & $2.86(3.14-2.20)$ \\
\hline Diet & $75(23.9 \%)$ & $107(1.97 \%)$ & & \\
\hline Insulin & $37(11.8 \%)$ & $59(1.08 \%)$ & & \\
\hline Macrosomia (>3.5 kg) & $144(45.9 \%)$ & $1203(22.2 \%)$ & 0.0002 & $1.10(0.85-1.36)$ \\
\hline \multicolumn{5}{|l|}{ Mode of delivery } \\
\hline Cesarean section & $236(75.2 \%)$ & $3540(65.4 \%)$ & 0.001 & \\
\hline Emergency LSCS & $136(43.3 \%)$ & $2200(40.6 \%)$ & & \\
\hline Elective LSCS & $97(30.7 \%)$ & $1343(24.8 \%)$ & & \\
\hline NVD & $78(24.8 \%)$ & $1873(34.6 \%)$ & & \\
\hline
\end{tabular}

Table 3: Distribution of BMI classes among obese group.

\begin{tabular}{|c|c|c|c|}
\hline $\begin{array}{l}\text { BMI } \\
\text { class }\end{array}$ & BMI $\left(\mathrm{kg} / \mathrm{m}^{2}\right)$ & $\begin{array}{l}\text { No. of pregnant } \\
\text { women }\end{array}$ & Percent \\
\hline Class-I & $30-34.9$ & 239 & 76.1 \\
\hline Class-II & $35-39.9$ & 59 & 18.8 \\
\hline Class-III & $40+$ & 16 & 5.1 \\
\hline
\end{tabular}

The complications such as gestational hypertension, preeclampsia and GDM increased significantly as BMI increased which was comparable with other studies.

The incidence of emergency LSCS in all the groups increased as BMI increases such as $(41 \%, 49.2 \%$ and $56.2 \%$ ) in class I, class II and class III respectively, which is found to be statistically significant with $\mathrm{p}$ value $=0.0001$. But the incidence of elective LSCS, it is higher in class III $(37.5 \%)$ followed by class I $(31.8 \%)$ and then by class II (25.4\%) which is not statistically significant (p value $=0.145)$.

The incidence of macrosomia increases as BMI increases seen as $41 \%$ in class I with a drastic increase to $62.10 \%$ in class II and $62.5 \%$ in class III.

However, the $\mathrm{p}$ value for this increase in incidence $=0.006$, which is not statistically significant (Table 4$)$.

Out of $n=314$ obese pregnant women only $133(42.3 \%)$ were without any antenatal complications such as hypertensive disorders and gestational diabetes, out of 
which $9.02 \%$ obese pregnant women not even had other complications like macrosomia and operative delivery.
$90.98 \%$ of the obese group had at least any one of the 4 complications discussed above.

Table 4: Distribution of complications in different classes of BMI.

\begin{tabular}{|c|c|c|c|c|c|}
\hline & $\mathbf{N}=314$ & Class $1(n=239)$ & Class $2(n=59)$ & Class $3(n=16)$ & P value \\
\hline Gestational hypertension & $53(16.9 \%)$ & $30(12.6 \%)$ & $17(28.8 \%)$ & $6(37.5 \%)$ & 0.001 \\
\hline \multicolumn{5}{|l|}{ Pre-eclampsia } & 0.001 \\
\hline Mild & $52(16.6 \%)$ & $30(12.6 \%)$ & $16(27.1 \%)$ & $6(37.5 \%)$ & \\
\hline Severe & $23(7.3 \%)$ & $14(5.9 \%)$ & $6(10.2 \%)$ & $3(18.8 \%)$ & \\
\hline \multicolumn{5}{|c|}{ Gestational diabetes mellitus } & 0.0003 \\
\hline Diet & $75(23.9 \%)$ & $50(20.9 \%)$ & $16(27.1 \%)$ & $9(56.2 \%)$ & \\
\hline Insulin & $37(11.8 \%)$ & $24(10 \%)$ & $8(13.6 \%)$ & $5(31.2 \%)$ & \\
\hline Macrosomia & $144(46 \%)$ & $98(41 \%)$ & $36(62.1 \%)$ & $10(62.5 \%)$ & 0.006 \\
\hline \multicolumn{6}{|l|}{ Mode of delivery } \\
\hline NVD & $78(24.8 \%)$ & $64(26.8 \%)$ & $13(22 \%)$ & $1(6.2 \%)$ & \\
\hline Elective LSCS & $97(30.9 \%)$ & $76(31.8 \%)$ & $15(25.4 \%)$ & $6(37.5 \%)$ & 0.145 \\
\hline Emergency LSCS & $136(40.3 \%)$ & $98(41 \%)$ & $29(49.2 \%)$ & $9(56.2 \%)$ & 0.0001 \\
\hline Instrumental & $3(1 \%)$ & $1(0.5 \%)$ & $2(3.5 \%)$ & $0(0)$ & \\
\hline
\end{tabular}

Only pre-eclampsia is seen $14.1 \%$ of obese women which significantly increases as BMI increases in different classes of obese group as $12.9 \%, 16.9 \%$ and $18.5 \%$ in class I, class II and class III respectively. Only GDM is seen in $22.3 \%$ of obese women but there is no stastically significant increase in the incidence between class I and class II, but a marked increase is seen in Class III $(21.75 \%, 20.3 \%$ and $37.5 \%$ respectively (Figure 1$)$.

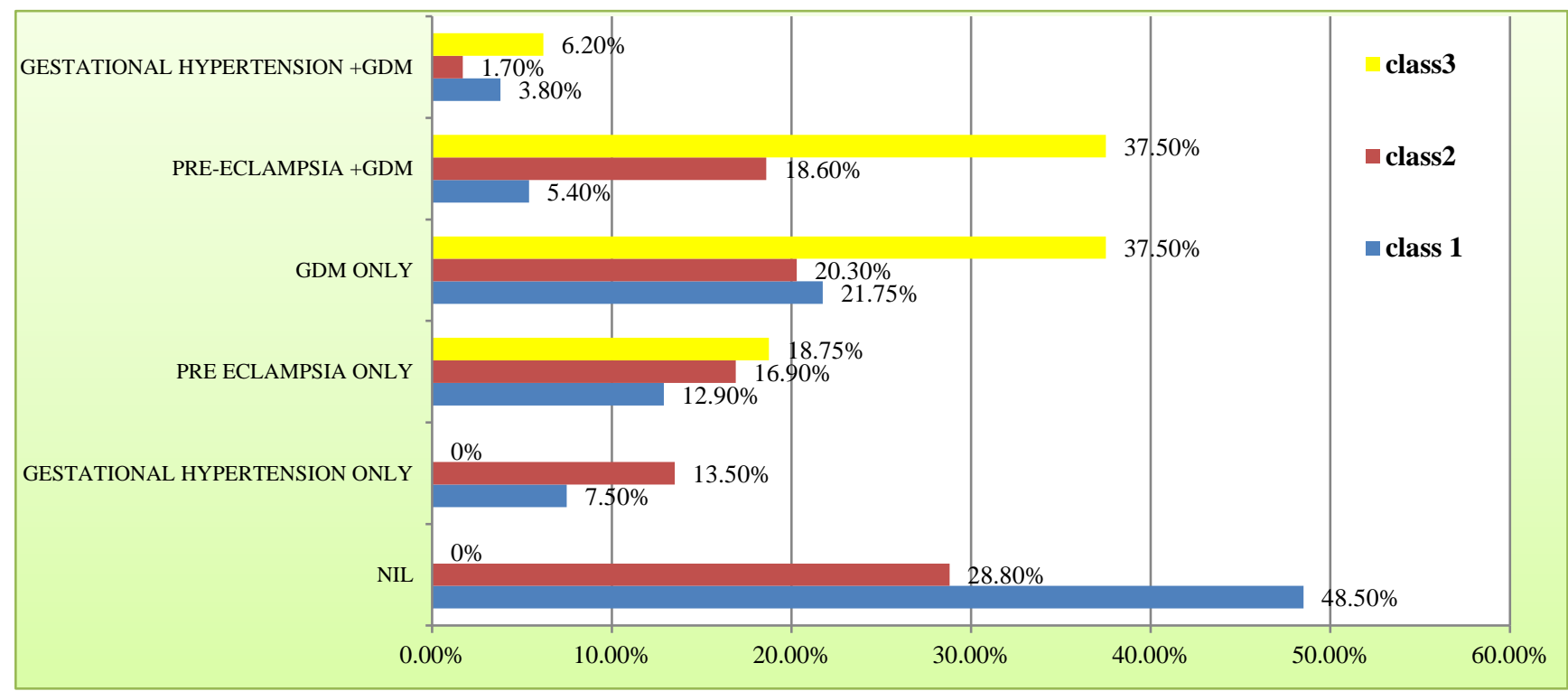

Figure 1: Combination of complications in different classes of BMI.

Presence of all four complications such as GDM, preeclampsia, macrosomia and caesarean section are present in $8.6 \%$ of obese pregnant women $(n=314)$. The presence of all four complications in obese group $(n=314)$ increases with increase in BMI which is seen as
$7.1 \%, 8.5 \%$ and $31.2 \%$ in class I, class II and class III respectively. $\mathrm{P}$ value for increase in the incidence of presence of all 4 complications $=0.004$ which is statistically significant (Figure 2). 


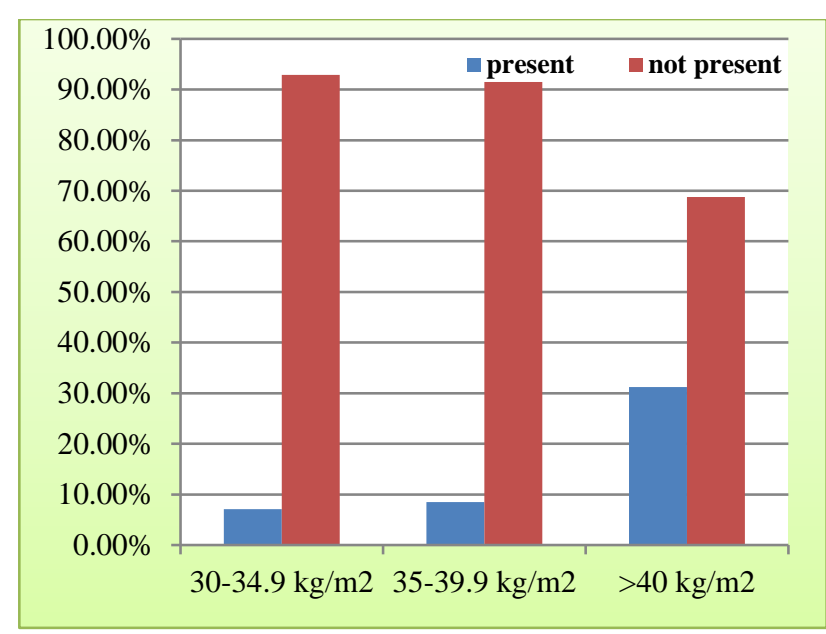

Figure 2: combination of all four complications among obese women.

\section{DISCUSSION}

Obesity has become epidemic proportions in India in the $21^{\text {st }}$ century, affecting $5 \%$ of the country's population. The percentage of childbearing obese women is increasing, and it is estimated that at least $22 \%$ of women ages 20-39 years are either overweight or obese. ${ }^{6}$ The present study identified the incidence of obesity in our hospital with $5.48 \%(\mathrm{n}=314)$ of singleton pregnancies delivered at term.

Pre-pregnancy weight may have some impact on woman's weight during her pregnancy; specifically, if a woman is obese prior to becoming pregnant, is likely to remain obese during pregnancy and likely to result with poor pregnancy outcomes.

The mean age of the present study is 26.9 which was comparable to other studies such as Mandal et al (26.8) and Teresa et al (12.32). ${ }^{8}$ The present study revealed that the parity analysis is similar to the studies by Dasgupta et al and Mandal et al, that the BMI gradient did not differ by parity. ${ }^{8,9}$

There is a significant increase in gestational hypertension in obese population compared to non-obese group (16.9\% vs $2.1 \%$ ), which is found to be significant with an odd's ratio of 2.3 comparable to that of study done by Dasgupta et al (Table 5). The incidence of gestational hypertension increases as BMI increases significant p value of $0.001 .^{9}$

Pre-eclampsia in antenatal period is higher in obese women (mild PIH of $16.6 \%$ and severe PIH of $17 \%$ ), when compared to non-obese women (mild PIH of $3.5 \%$ and severe PIH of $2.1 \%$ ) with the $\mathrm{p}$ value $<0.0002$. Similarly, Sebire et al (2001) reported in their study, a 24-fold increase in preeclampsia in obese women. ${ }^{11}$

Brien et al, reported that the risk of preeclampsia typically doubled with each $5-7 \mathrm{~kg} / \mathrm{m}^{2}$ increase in maternal BMI. ${ }^{12}$ There was a linear trend of increase in incidence of pre-eclampsia which is seen similar to that observed by Yogev and Catalano. ${ }^{5}$

In general, $1-3 \%$ of all pregnancies are diagnosed to have gestational diabetes, while in obese women it is found to be approximately $17 \%$ according to Gabee et al. ${ }^{13}$ In the present study GDM was significantly seen in $35.7 \%$ of obese pregnant women contrary to $3.1 \%$ in non-obese pregnant women.

The odd's ratio for this association being 2.86 comparable with study by Sebire et al who had shown an odd's ratio of 3.5 and Dasgupta et al shown an odd's ratio of 5 in their studies. ${ }^{9,11}$ The magnitude of this risk positively correlating with increase in maternal weight is also seen in the meta-analysis of 20 studies examined by Chu et al and his associates and our study also shows increase in incidence is significant with $\mathrm{p}$ value $=0.0003 .{ }^{14}$

The present study is in accordance with the study of Ehrenberg who reported a higher chance of caesarean delivery in obese women $(13.8 \%$ versus $7.7 \%, \mathrm{P}$ $<0.0001) .^{15}$

Out of 314 obese women $44.6 \%$ underwent emergency LSCS with most common indication being fetal distress and failed induction, and $30.7 \%$ underwent elective LSCS with most common indication being cephalo pelvic disproportion.

Most of the studies carried by Mandal et al, Teresa et al (Table 5) showed that, Emergency LSCS was particularly increased with increasing BMI but the present study showed that there is no significant increase in the rate of emergency LSCS when compared to that of non-obese.

Table 5: Comparison with other studies.

\begin{tabular}{|llllll|}
\hline & Gestational hypertension & Pre-eclampsia & GDM & Macrosomia & Cesarean delivery \\
\hline Kumari et al & $28.8 \%$ & - & $24.5 \%$ & $32.6 \%$ & $15.2 \%$ \\
\hline Mandal et al & $12.32 \%$ & $8.76 \%$ & $19.43 \%$ & $22.28 \%$ & $58 \%$ \\
\hline Dasgupta et al & $36.9 \%$ & $18 \%$ & $26.9 \%$ & $2.47 \%$ & $33.8 \%$ \\
\hline Vijay et al & - & $36 \%$ & $8 \%$ & $16 \%$ & $44 \%$ \\
\hline Present study & $16.9 \%$ & $23.9 \%$ & $35.7 \%$ & $46 \%$ & $75.2 \%$ \\
\hline
\end{tabular}


Sheiner et al stated that after having adjusted for diabetes mellitus, no significant association was found between macrosomia and obesity alone. ${ }^{16}$ Besides, Catalano had already demonstrated that GDM can be a confounding factor in between macrosomia and obesity. In an analysis of a multi-country, facility based, cross-sectional survey of macrosomia in 23 developing countries, the cut off for macrosomia for Indian population is taken as $\geq 3.5 \mathrm{~kg}$. ${ }^{17}$

In the present study, the results showed a significant association between macrosomia (b.wt $>3.5 \mathrm{~kg}$ ) and obesity with odds ratio of 1.10 , however there was no linear trend of increase in macrosomia in different classes of obese group.

Combination of pre-eclampsia and GDM is seen in $9.6 \%$ of obese pregnant women and this association increases as BMI increases seen as $5.4 \%, 18.6 \%$ and $37.5 \%$ in class I, class II and class III obese groups respectively. This is in concurrence with the study of Weiss and associates (FASTER Trial, 2004) which showed a marked increase in pre-eclampsia and diabetes of class I $(10.2 \%$ and $12.3 \%)$ and class II $(6.3 \%$ and $9.5 \%) .{ }^{18}$

\section{CONCLUSION}

The higher incidence of pregnancy complications in obesity is well established by many studies and this study also correlates with most of them. Hence obesity being a modifiable risk factor, interventions such as preconceptional counselling, pre-conceptional weight loss and recommended pregnancy weight gain can be helpful in achieving the goal, a healthy mother and a healthy baby.

\section{Funding: No funding sources}

Conflict of interest: None declared

Ethical approval: The study was approved by the Institutional Ethics Committee

\section{REFERENCES}

1. World Health Organization. Obesity and Overweight. Fact sheet N 311, January 2015

2. Garg C, Khan SA, Ansari SH, Garg M. Prevalence of obesity in Indian women. Obes Rev. 2010;11(2):105-8

3. Pradeepa R, Anjana RM, Joshi SR, Bhansali A, Deepa M, Joshi PP, et al. Prevalence of generalized and abdominal obesity in urban and rural India- the ICMR INDIAB Study (Phase-I) (ICMR - INDIAB-3). Indian J Med Res. 2015;142:139-50.

4. Gregory AL, Davies, Kingston ON, Cynthia Maxwell, Toronto ON Lynne. McLeod S OGC practice guidelines. 2010:239.

5. Hedley AA, Ogden CL, Johnson CL, Carroll MD, Curtin LR, Flegal KM. Prevalence of overweight and obesity among US children, adolescents, and adults, 1999-2002. JAMA. 2004;291(23):2847-50.

6. Yogev Y, Catalano PM. Pregnancy and obesity. Obstetr Gynecol Clin. 2009;36(2):285-300.

7. Flegal KM, Carroll MD, Ogden CL, Curtin LR. Prevalence and trends in obesity among US adults, 1999-2008. JAMA. 2010;303(3):235-41.

8. Kumari AS. Pregnancy outcome in women with morbid obesity. Int J Gynae Obstet. 2001;73(2):101-7.

9. Mandal D, Manda S, Rakshi A, Dey RP, Biswas SC, Banerjee A. Maternal obesity and pregnancy outcome: a prospective analysis. J Assoc Physicians India. 2011;59:486-9.

10. Dasgupta A, Harichandrakumar KT, Habeebullah S. Pregnancy outcome among obese Indians-a prospective cohort study in a tertiary Care Centre in South India. Int J Sci Stud. 2014;2(2):13-8.

11. Vijay A, Maran G, Koothan V. Impact of maternal obesity on obstetric outcome in a rural population in Pondicherry. Int J Rep Contracept Obstet Gynecol. 2017;4(3):740-4.

12. Sebire NJ, Jolly M, Harris JP, Wadsworth J, Joffe M, Beard RW, et al. Maternal obesity and pregnancy outcome: a study of 287213 pregnancies in London. Int J Obes. 2001;25(8):1175.

13. O'Brien TE, Ray JG, Chan WS. Maternal body mass index and the risk of preeclampsia: a systematic overview. Epidemiol. 2003:368-74.

14. Gabbe S. Gestational diabetes mellitus. N Engl J Med. 1986;315:1025-6

15. Chu SY, Callaghan WM, Kim SY, Schmid CH, Lau J, England LJ, et al. Maternal obesity and risk of gestational diabetes mellitus. Diab Care. 2007;30(8):2070-6.

16. Ehrenberg HM, Mercer BM, Catalano PM. The influence of obesity and diabetes on the prevalence of macrosomia. Am J Obstet Gynecol. 2004;191(3):964-8.

17. Sheiner E, Levy A, Menes TS, Silverberg D, Katz M, Mazor M. Maternal obesity as an independent risk factor for caesarean delivery. Paediat Perinat Epidemiol. 2004;18(3):196-201.

18. Koyanagi A, Zhang J, Dagvadorj A, Hirayama F, Shibuya K, Souza JP, Gülmezoglu AM. Macrosomia in 23 developing countries: an analysis of a multicountry, facility-based, cross-sectional survey. Lancet. 2013;381(9865):476-83.

19. Weiss JL, Malone FD, Emig D, Ball RH, Nyberg DA, Comstock $\mathrm{CH}$, et al. Obesity, obstetric complications and cesarean delivery rate: a population-based screening study. Am J Obstet Gynecol. 2004;190(4):1091-7.

Cite this article as: Thota AR, Bhandiwad A, Sakhireddy V. Short term effects of maternal obesity on mother and fetus: a prospective study. Int $\mathbf{J}$ Reprod Contracept Obstet Gynecol 2018;7:3097-102. 